\title{
Is There Any Customer Switching the Intention from Traveloka PayLater to Traveloka PayLater Card? A Preliminary Investigation on Worker in Jakarta
}

\author{
Gidion P. Adirinekso ${ }^{1 *}$, Adrie F. Assa ${ }^{1}$ \\ ${ }^{1}$ Faculty of Economics and Business, Universitas Kristen Krida Wacana, Jakarta - 11470, Indonesia \\ ${ }^{*}$ Corresponding author. Email: gidion.adirinekso@ukrida.ac.id
}

\begin{abstract}
The launch of the Traveloka PayLater Card in September 2019 by Traveloka in collaboration with Bank Rakyat Indonesia (BRI) was one of the efforts to improve the digital payment services. PayLater Card's emergence was expected to increase the number of members to reach 5 million by 2025, considering that BRI is a bank with the most extensive network. It is interesting to know the Traveloka customers' behavior, whether the customers who use the PayLater will switch to the PayLater Card. This study was conducted in Jakarta in March 2020. This study used a push-pull-mooring (PPM) framework to show the determinants of Traveloka customers' switching behavior from PayLater to PayLater Card. The Structural Equation Modelling was conducted on the data that was collected from 1,117 workers using PayLater Card in the Jakarta Special Region. This study shows that all variables in second-order, like push, pull, and mooring-effect, don't cause switching intention significantly from PayLater to PayLater Card. However, all variables in the first-order explain the second-order variables. The aesthetic design explains the push effect. Economic benefit, convenience for the transaction, gamification, and locatability cause the pull-effect. Inertia and perceived substitutability cause the mooringeffect. For further research, it is recommended to compare the appropriate higher-order model and then select the most-appropriate variable in the push-pull-mooring framework.
\end{abstract}

Keywords: switching intention, push-pull-mooring, PayLater Card

\section{INTRODUCTION}

At present, when the digital era covers all the aspects of life, including in business, mostly when it is associated with the COVID-19 pandemic, it dramatically affects the dynamics of business development. For this reason, the business sector must innovate marketing strategies related to the trend of digital mobile services [1].

Traveloka has made changes to the payment method in its business. If previously Traveloka customers used the PayLater application, then in September 2019, collaborating with Bank Rakyat Indonesia (BRI), one of the banks with the broadest network in Indonesia, issued a PayLater Card [2].

A credit card is designed to make the users easier. Besides being practical and can be used in an emergency situation, the transaction tool can also be used to help users evaluate their expenses. Every month the bank will send a bill along with all the details so that users can judge for what purposes their income is spent. However, in many ways, convenience also has an unfortunate effect. Without real transaction notification - things like that then can make users unaware of the number of transactions - and the need to pay an annual fee are examples of how having a credit card is often considered a boomerang by its users.
This kind of problem is what Traveloka PayLater Card tries to solve. President of the Traveloka Group, Mr. Henry Hendrawan, said that apart from providing an innovative user experience, the new product is also expected to provide solutions to Traveloka users' obstacles. The advantages of the product offered, in addition to online transactions on the Traveloka PayLater Card, can be used in 53 million locations around the world that accept payments via Visa. PayLater Card is a credit solution with real-time control by the customer [3]. This good product is offered to PayLater customers who have never been overdue.

Does the product excellence offered to Traveloka customers, PayLater users who have never had a problem with their transactions, immediately switch to the PayLater Card? Does the appeal of the PayLater Card encourage customers to use it? What is the driving force for the customer to switch to the new product? These questions need to be answered, even if there is no customer movement. This understanding of switching behavior is important not only for the brand manager to anticipate customer voices but also to develop strategies to retain customers through interesting fintech services.

To answer some of these problems, we would use the pullpush-mooring (PPM) framework, which has been widely applied in various studies. Some of them are technological products [4], the aviation industry [5], and social-network 
sites [6]. This study examined the switching behavior between company products. In particular, this study would examine the self-switching behavior of customers of a company, as was done by [7].

Traveloka is one of the early unicorns [8] in Indonesia became the subject of this research because, at the same time, customers were given the opportunity to become members of the Traveloka PayLater Card and Traveloka PayLater, which were introduced to the customer first. On the other hand, even though Traveloka PayLater Card provides many conveniences, from consumers' voices there are still many complaints just about the registration matter.

\subsection{Related Work}

The studies related to the shift between membership cards and car applications using the ppm approach, for example, were carried out by [7] on a Starbucks case in Taiwan, [9] on the shift in car-payment service-platforms in Taiwan, [10] on replacement of online services by bloggers to socialnetwork sites. Meanwhile, [11] examined the shift in payment methods from internet-payment to mobilepayment, and [12] observed the consumer switching behavior towards mobile shopping. All these researchers used a push-pull-mooring framework in explaining the displacement that occurred.

\subsection{Our Contribution}

This research was expected to contribute to the moving behavior of a person related to the payment methods for Traveloka customers. If it is proven that there are factors that influence the displacement, it is hoped that managerial implications will arise. The studies on the transfer of payment methods by customers for the same product have been relatively under-studied, especially in Indonesia.

\subsection{Paper Structure}

The rest of this paper is organized as follows: Section 2 contains the theoretical background, including the PPM framework and hypothesis development; Section 3 describes the research methodology; Then in Section 4, is the results; Finally, Section 5 contains the conclusions of this paper as well as the future research directions.

\section{THEORETICAL BACKGROUND}

\subsection{The PPM Framework}

As a dominant paradigm in migration research [7], PullPush-Mooring has identified negative factors that will push the people away. Low satisfaction, quality value, trust, commitment, and high price perceptions are the examples of push-factors. Meanwhile, other factors which can attract people is the pull-factors, including the mooring variables like personal variables or contextual constraints in the PPM framework [13]. The application of PPM framework to investigate the customers' switching behavior has been developed by [7]. It will now be implemented to capture the switching behavior between Traveloka PayLater and Traveloka PayLater Card.

Push-factors refer to the aesthetics design [14], and adopt the indicators by [7]. Aesthetics is defined as "the feelings, concepts, and judgment arising from an appreciation of the arts or of the broader class of objects considered moving, or beautiful, or sublime". It means that an aesthetic design provides the intangible benefit related to the psychological needs [15]. The consumer will evaluate more favorable products endowed with aesthetically pleasing from those lacking such styling. If the products have a poor aesthetic design, it will push the customer away from using PayLater Card.

Pull-factors include the local ability, transaction convenience, economic benefits, and gamification. Those pull-factors motivate the customer to switch from Traveloka PayLater Card to Traveloka PayLater. Locatability or usefulness will capture the ease of getting up-to-date information, accessibility for relevant information, and timely information [16]. If customers quickly complete their purchase, are quick to complete the transaction, and need a little time to make a transaction, then they will be convenient in the transaction [17]. After that, financial gain, lower financial cost, less spending, and saving customers' money will reflect their economic benefits [17]. Gamification in this study adopts from [18]. Customers feel clear about the purchasing and reward, varying reward, automatic notifications, and retrievable experiences.

Mooring-factors are substitutability and inertia. Customer switching is a complex decision, even though pull or pushfactors are substantial. [7] defined the mooring-effects as switching barriers because these represent forces that make switching becomes difficult or costly. Substitutability in this study represents the ability of the Traveloka PayLater Card to compensate Traveloka PayLater. If customers are satisfied with the same need but in different forms, then those two products are substitutable. Meanwhile, the inertia in this study focused on the consumption patterns associated with various services under a single brand, namely Traveloka. The research framework in this study refers to [7] as shown in Figure 1.

\subsection{Hypotheses}

When a product's design appeals to the customers, they effectively connect with the outcome and visually improve the customers' experience. A better aesthetic communicates the service attribute more positively, leading to customer perception of increased usability [15]. The visual appeal of the product influences consumer perception and behavior [19]. If the design of PayLater membership card is low, then the consumers cannot receive the value that compensates for drawbacks in functionality. Therefore, the aesthetic design will push the switching intention.

$\mathrm{H}_{1}$ : Aesthetic Design associated with Traveloka PayLater influences the customer switching intention with Traveloka PayLater membership card. 


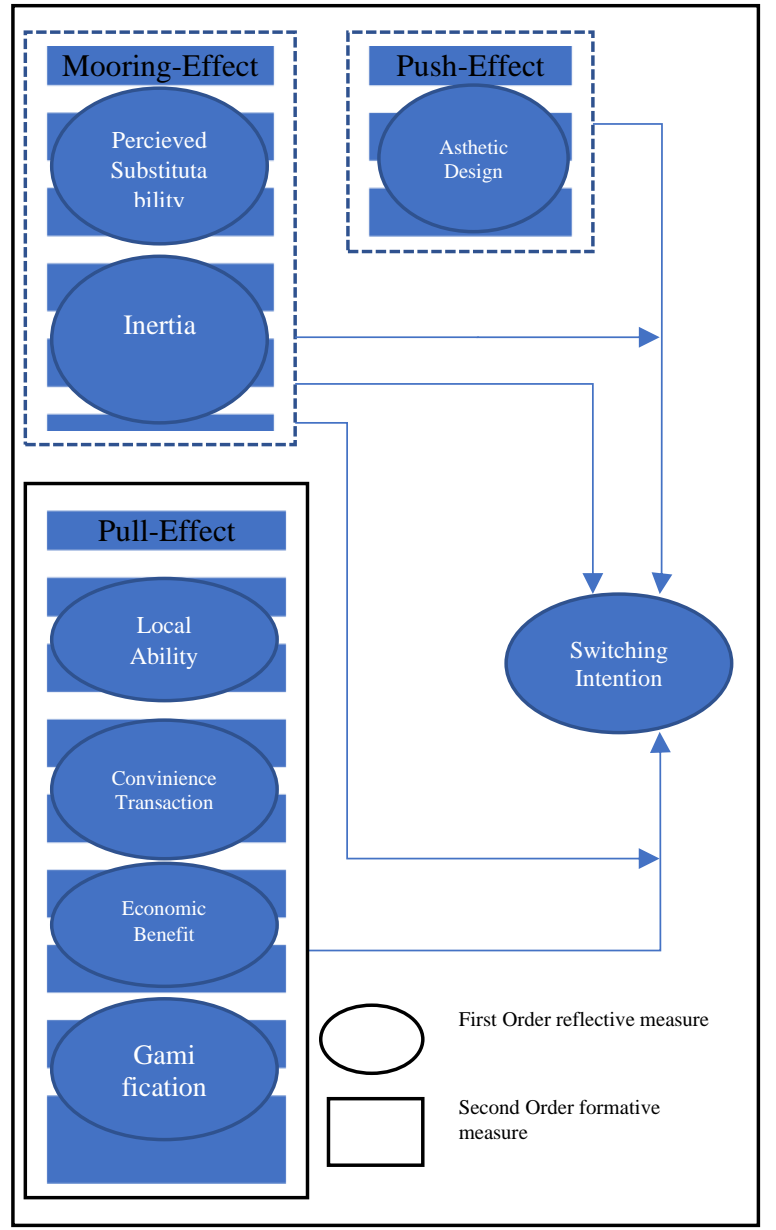

Figure 1 The Research Framework

[20] stated that consumers consider switching when a substitute service offers relative advantages over the existing service. If Traveloka PayLater Card gives many benefits to consumers, it will push them to change. The locatability or usefulness in using navigational services creates benefits for consumers [21]. Consumers can receive the information based on their current location; it means that Traveloka PayLater Card will give precise information about their transactions. The locatability of the Traveloka PayLater Card will push consumers to switch from the old one.

$\mathrm{H}_{2}$ : Locatability influences the switching intention of customers.

In the current modern world, all consumers need convenience to make the transaction more practical, straightforward, and easy-to-use. [22] also proposed that the potential for enhanced performance stimulates the consumers' switching intention. We have known that Traveloka PayLater Card also has some advantageous features than Traveloka PayLater. When consumers feel the convenience of doing a transaction for new services, they will switch to the new ones. As [23] said, transaction convenience affects users' performance expectations and will influence their intention.

$\mathrm{H}_{3}$ : Transaction convenience of Traveloka PayLater Card influences the customers to switch their intention.

Traveloka PayLater Card provides some benefit to the customers. It will perform in monetary value [24], gaining financial savings [25]. Consumers choose their choice, and they will consider the price as big-weighted than others [26]. From those perspectives, the following hypothesis could be developed as follow:

$\mathrm{H}_{4}$ : Economic Benefit influences the customers' switching intention.

The last pull-factor in the PPM framework is gamification [7]. As a marketing strategy, gamification adds game elements to the non-game environment, product, or services. It is like an extra value [27] that motivates the consumers to exhibit the desired behaviors [28]. The impact of gamification on consumer behavior is explicitly found in entertaining customers, accelerating purchase, and retaining consumers. They improve customer motivation and engagement in performing a particular task [29] and increase customer loyalty and better customer experiences [30].

$\mathrm{H}_{5}$ : Gamification influences the customer switching intention to Traveloka PayLater Card.

Another factor that causes customers to switch to other applications is the mooring in the application's substitution capability. If the usability, convenience, and similarities between Traveloka PayLater Card and Traveloka PayLater are the same, this will be a mooring for customers to move. The consumer perception of substitutability affects their attitude toward brand extension [31]. If two products or services are substitutable, an increase in one product or service activity may reduce the marginal benefit received from the other [32]. The substitutability will affect purchase intention [33]. This study proposed that perceived substitutability positively influences the customers' intention to switch from PayLater to PayLater Card.

$\mathrm{H}_{6}$ : Perceived Substitutability influences the customers' switching intention from Traveloka PayLater to PayLater Card.

Consumers who already have a good perception of a product or service are reluctant to look for other products or services. If Traveloka PayLater users have a good perception of it, they will be unwilling to switch to Traveloka PayLater Card. They will be reluctant to switch to a new product because they do not analyze the choice of the products [34]. Therefore, the intention switching will be negatively affected by these inertia consumers.

$\mathrm{H}_{7}$ : Inertia has a negative influence on customers' switching intention from Traveloka PayLater to PayLater Card. 


\section{RESEARCH METHODOLOGY}

In this study, the measurement of a construct, as an abstraction of a phenomenon or reality, would be operationalized in a form that can be measured by a variety of values. The operational definition is an explanation of the specific ways in which researchers operate to operationalize the constructs into testable variables. The constructs that are operationalized into variables can be measured using the numbers or attributes that use a Likert scale. The Likert scale can measure the attitudes, opinions, and perceptions of a person or group of people about a symptom or phenomenon [35]. All questionnaires related to main variables use close questions with a five-point Likert scale. The questionnaire was adapted from [7] along with some adjustments regarding the different research objects.
The convenience sampling method was used in this study. The Authors surveyed the Traveloka customers in March 2020 who have used PayLater and now PayLater Cards. The sample was taken from the urban worker as Traveloka customers living in the Jakarta Special Region.

In this study, PLS-SEM was used as analytical data method, which has been applied in many marketing research. Structural Equation Modelling (SEM) is currently used to cover the regression method's weaknesses [36]. SEM is an evolution of multiple-equation models developed from econometrics principles and combined with the organizing principles of psychology and sociology [36]. SEM has emerged as an integral part of academic and managerial research. This study's indicator approach combines the reflective and formative approaches, whereas the indicators can reflect latent variables.

Table 1 Construct Validity \& Reliability

\begin{tabular}{|l|c|c|c|c|c|}
\hline & Items & Loadings & AVE & CR & Rho_A \\
\hline Push-Effect & & & $\mathbf{0 . 6 8 9}$ & $\mathbf{0 . 8 9 9}$ & $\mathbf{0 . 8 5 0}$ \\
\hline Aesthetic Design_ & AD1 & 0.809 & 0.689 & 0.899 & 0.850 \\
\hline & AD2 & 0.840 & & & \\
\hline & AD3 & 0.827 & & & \\
\hline Mooring-Effect & AD4 & 0.843 & & & \\
\hline Perceived Substitutability & & & $\mathbf{0 . 5 1 9}$ & $\mathbf{0 . 8 8 2}$ & $\mathbf{0 . 8 4 5}$ \\
\hline & PS1 & 0.725 & 0.643 & 0.900 & 0.861 \\
\hline & PS2 & 0.759 & & & \\
\hline & PS3 & 0.788 & & & \\
\hline & PS4 & 0.788 & & & \\
\hline Inertia_ & PS5 & 0.779 & & & \\
\hline & IN1 & 0.849 & 0.698 & 0.822 & 0.571 \\
\hline Pull-Effect & IN2 & 0.822 & & & \\
\hline Locatability & & & & & $\mathbf{1 0 0 0}$ \\
\hline & L1 & 0.906 & & & 1000 \\
\hline Convenience for Transaction_ & L2 & 0.913 & & & \\
\hline & CT1 & 0.842 & & & 1000 \\
\hline Benefit & CT3 & 0.918 & & & \\
\hline & B2 & 0.893 & & & 1000 \\
\hline Gamification & B3 & 0.919 & & & \\
\hline & G3 & 0.873 & & & 1000 \\
\hline Moderating Pull-Effect & G4 & 0.846 & & & \\
\hline Moderating Push-Effect & & $\mathbf{1 0 2 2}$ & $\mathbf{1 0 0 0}$ & $\mathbf{1 0 0 0}$ & $\mathbf{1 0 0 0}$ \\
\hline Intention Switching & & $\mathbf{1 0 0 0}$ & $\mathbf{1 0 0 0}$ & $\mathbf{1 0 0 0}$ & $\mathbf{1 0 0 0}$ \\
\hline Soure:Data Ana & SI1 & $\mathbf{1 0 0 0}$ & $\mathbf{1 0 0 0}$ & $\mathbf{1 0 0 0}$ & $\mathbf{1 0 0 0}$ \\
\hline
\end{tabular}

Source: Data Analysis Results (2020)

An Outer-Model Test was carried out to ensure that the measurements used are appropriate measures (convergent and discriminant validity and reliability test). In the SEMPLS approach, a measurement meets convergent validity, if it has met several criteria, which are: Loading-factor parameters $>0.7$; Average Variance Extracted (AVE) parameter $>0.5$; Communality parameter $>0.5$ [37], and AVE value is higher than the squared-correlation [38]. 
Practically, the measurement of discriminant validity test is formulated as follows: AVE-root parameters and correlation of latent variables $>$ potential variable association; Cross-loading parameters $>0.7$ in one variable [39].

Reliability testing can use two methods, which are Cronbach's Alpha and composite reliability. Cronbach's alpha measures the lower limit of a construct's reliability value, while composite reliability measures the actual value of a construct's reliability. Alpha value or composite reliability is higher than 0.7 , although the amount of 0.6 is still acceptable [38].

Inner Model Test. These tests were carried out to test the relationship between the latent constructs. There are several structural or inner model tests. a) R Square > 0.67 (strong), 0.33 (moderate), 0.19 (weak); b) Estimate for Path Coefficients performed by the Bootstrapping procedure; c) Prediction Relevance (Q Square) or also known as StoneGeisser's. d). Q Square if the values obtained are 0.02 (small), 0.15 (medium) and 0.35 (large) [39].

Hypothesis testing. To test the hypothesis, we used the pvalue generated from the SEM-PLS test. The hypothesis will be accepted if the probability value is lower than the significance level of 0.05 . To test the hypotheses, we often use $\mathrm{p}<0.05$ rather than $\mathrm{p} \leq 0.05[40]$.

\section{RESULTS}

In this study, we used a higher-construct model. The aesthetic design, locatability, transaction convenience, economic benefit, gamification, substitutability, and inertia were conceptualized as first-order reflective constructs. Meanwhile, the pull-effect was conceptualized as a secondorder formative measurement construct.

Table 1 shows that the construct validity and reliability in the model have fulfilled the criteria. The validity and reliability values show the fulfillment of the requirements set for the construct validity and reliability. Some indicators like IN3, L3, L4, B1, B4, CT2, G1, G2, G5, L3, L4, SI2, SI3, SI4 were dropped because they didn't match the criteria of outer-loading.

Fornell-Larker and Heterotrait-monotrait (HTMT) were used to evaluate the discriminant validity. The HTMT values of Push-Effect - aesthetic design (0.85), mooringeffect-inertia (0.85), and perceived substitutability-mooring effect $(0.85)$ were minimal upper the predefined threshold of 0.85 . So, the criteria are still fulfilled in two digits, indicating that the primary constructs measured the different aspects.

This study also tested the potential multicollinearity among formative constructs items using the variance inflation factor (VIF). The value of VIF of all indicators is below the cut-off point of 3.3 [36] and [41], with maximum values of 2.5.

Table 2 shows the estimation results of the empirical model using the bootstrapping method. The results show that the processed data supports several hypotheses. The following is a detailed explanation for each path.

Table 2 Path Coefficients

\begin{tabular}{|l|c|c|}
\multicolumn{1}{|c|}{ Path Coefficient } & $\begin{array}{c}\text { Original } \\
\text { Sample (O) }\end{array}$ & p-Values \\
\hline Push-Effect -> Aesthetic Design & 1.000 & 0.000 \\
\hline Push-Effect -> Intention Switching & 0.033 & $\mathbf{0 . 3 0 0}$ \\
\hline Benefit -> Pull-Effect & 0.335 & 0.000 \\
\hline Convenience for Transaction -> Pull-Effect & 0.331 & 0.000 \\
\hline Gamification -> Pull-Effect & 0.335 & 0.000 \\
\hline Locatability_-> Pull-Effect & 0.210 & 0.000 \\
\hline Pull-Effect -> Intention Switching & 0.026 & $\mathbf{0 . 4 5 8}$ \\
\hline Mooring-Effect -> Inertia & 0.700 & 0.000 \\
\hline Mooring-Effect -> Perceived Substitutability & 0.959 & 0.000 \\
\hline Mooring-Effect -> Intention Switching & 0.048 & $\mathbf{0 . 1 2 4}$ \\
\hline Moderating Pull-Effect -> Intention Switching & -0.013 & $\mathbf{0 . 6 7 4}$ \\
\hline Moderating Push-Effect -> Intention Switching & 0.029 & $\mathbf{0 . 4 0 8}$ \\
\hline
\end{tabular}

Source: Data Analysis Results (2020)

Some research findings have been acquired. First, the pusheffect did not significantly affect the switching intention of the urban worker. The results of this study differ from [7] [10] [9]. The existence of a membership card should encourage consumers to switch from the usual payment methods. One possible reason is as a member of the Traveloka PayLater Card, the urban worker doesn't find an attractive card, professionally designed, visually appealing, and meaningful. Even all aesthetic design indicators significantly reflected the push-effect. The implication is 
that the aesthetic design is unsuitable as a push-factor, or another variable should be considered as a component of the push-effect.

Second, the pull-effect, in terms of economic benefit, the convenience of a transaction, gamification, and locatability, didn't affect the urban worker's switching intention. This result is inconsistent with [7] and [9]. The Traveloka PayLater Card offered provides comfort in e-commerce, but it does not provide economic benefits. The customers as a worker in urban areas feel that they are not getting financial services or reducing their financial costs, which reduces their expenses when using Traveloka PayLater Card. This result is essential for Traveloka and BRI Managers in designing Traveloka PayLater Cards as an early indication of the need for product improvement to be launched. Let's look at various sources on the internet, the complaints about the ease and speed for an urban worker which has become the customer to use Traveloka PayLater Card. Understandably, there is an uncomfortable perception. It could be a trigger factor why even though the product provided has more value, it becomes less attractive than the Traveloka PayLater app. A brand manager must extend its service-scope by integrating location-based services and other technological systems and fixing their registrationprocess problems, including improving their "togetherservice works" with BRI. As we know from Table 2, even though economic benefit, gamification, locatability, and convenience for transaction formed a pull-effect, urban worker pulls to use Traveloka PayLater Card, because it is easy to complete the transaction, more quickly and shorttime to conduct the purchase. However, these contributions didn't remove the customers as an urban worker. They feel little economic benefits like financial gain, lower financial cost, and spend the same time using Traveloka PayLater Card compared with Traveloka PayLater. Gamification includes actual notification, statistics about the progress, or status upgrade, which are relatively the same between using Traveloka PayLater Card and Traveloka PayLater. The indifference between those two products makes customers as the urban worker stays with the previous method to conduct their transactions. A similarity in the service between Traveloka PayLater Card and Traveloka PayLater app is the confusion of providing pull-effect to the urban worker. Traveloka PayLater apps have offered up-to-date information, the ability to access information, and on-time knowledge. Then, the pull-effect insignificantly affects the switching intention. The general functionality of PayLater cardholders to make an online or offline transaction in a million merchants will confuse them to know their switching intent.

Third, inertia and substitutability are the moorings for the urban worker. The influence of the inertia variable on the mooring-effect arises from customer satisfaction with Traveloka PayLater and using it to shop for flight tickets at Traveloka. Meanwhile, the substitution-rate for Traveloka PayLater Card is relatively high for Traveloka PayLater. The replacement arises from the same services provided, the same method, providing the same satisfaction, the same situation, and almost the same tools. However, this mooring variable is not significant in influencing the switching intention, but it becomes a factor that is considered by the urban worker. It means that the function of the PayLater Card can substitute the PayLater apps. This result doesn't support other studies conducted by [7] [9] [11].

Forth, the mooring-effect variable, in this study, cannot be a moderating variable for the push and pull-effect on intention switching. It means that inertia and perceived substitutability don't increase or decrease the impact of push and pull-effect on intention switching. This result is different from the findings of [7] and [9], which are able to increase the push and pull-effect on intention switching. Last, the mooring-effect itself does not affect the changing of the behavior of the urban worker from using Traveloka PayLater to using Traveloka PayLater Card. In this study, the mooring-effect is only potential to be a moderating variable.

\section{CONCLUSIONS}

Based on the above discussion, three things can be addressed for the following research. The first is related to the facts or data used, and the second is associated with the model used. Points in the field or the data used in this study did not support the theory applied under the PPM framework. Second, it is better to make comparative studies among the four higher-order model models [42] used in this study, which are the higher-order forms between the reflective and formative choices in the higher-model [42]. The best model in the push-pull-mooring framework will need to be reviewed before being implemented in some cases in Indonesia, especially the Traveloka PayLater and PayLater Cards. Third, we should choose another variable as a reflection or formation of the push-effect. The pulleffect or mooring-effect can use exploratory research [43] due to their characteristics [44] [45]. A simple model might provide evidence of changes in urban worker behavior in switching to Traveloka PayLater Card [46].

\section{REFERENCES}

[1] J. Heo and K. Kim, "Development of a Scale to Measure the Quality of mobile location-based services.," Service Business, pp. 141 - 159, 2017.

[2] www.tirto.id, "tirto.id," 30 March 2020. [Online]. Available: https://tirto.id/kartu-sakti-traveloka-paylatercard-eJKB. [Accessed October April 2020].

[3] Traveloka, "Traveloka.com," Traveloka, 1 May 2020. [Online]. Available:

https://www.traveloka.com/id-id/paylatercard/consent. [Accessed 13 September September 2020].

[4] K. Wu, J. Vassileva and Y. Zhao, "Understanding Users Intention to Switch personal cloud storage 
services: Evidence from Chinese market," Computers in Human Behavior, vol. 68, pp. 300 - 314, 2017.

[5] J. Jung, H. Han and M. Oh, "Travelers Swicthing behavior in the airline industry from the perspective og the push-pull-mooring framework," Tourism Management, vol. 59, pp. 139-153, 2017.

[6] Y. Xu, Y. Yang, Z. Cheng and J. Lim, "Retaining and Attracting users in social networking services: An empirical investigation of cyber migration," The Journal of Strategic Information Systems, vol. 23, no. 3, pp. $239-253,2014$.

[7] C.-Y. Li, “Consumer Behavior in Switching between Membership Cards and Mobile Applications: The Case of Starbucks," Computer in Human Behavior, vol. 84, no. July, pp. 171-184, 2018.

[8] Y. Ramadhani, “tirto.id,” 18 Februari 2019. [Online]. Available: https://tirto.id/3-unicorn-pertamaindonesia-gojek-tokopedia-dan-traveloka-dhfB. [Accessed 3 May 2020].

[9] R.-Z. Kuo, "Why do people switch mobile payment service platforms? An empirical study in Taiwan," Technology in Society, vol. 62, pp. 1 - 16, 2020.

[10] J.-K. Hsiesh, Y.-C. Hsieh, H.-C. Chiu and Y.-C. Feng, "Post-adoption switching behavior for online service substitutes: A perspective of the push-pullmooring framework," Computer in Human Behavior, vol. 28, pp. 1912 - 1920, 2012.

[11] L. Fan, X. Zhang, L. Rai and Y. Du, "Mobile Payment: The Next Frontier of Payment Systems? - An Empirical Study Based on Push-Pull-Mooring Framework," JOurnal of Theoretical and Applied Electronic Commerce Research, vol. 16, no. 2, pp. 155 - 169, 2021.

[12] J.-Y. Lai, S. Debbarma and K. R. Ulhas, "An empirical study of consumer switching behaviour towards mobile shopping: a Push-Pull-Mooring model," International Journal Mobile Communication, vol. 10, no. 4, pp. $386-404,2012$.

[13] B. Moon, "Paradigms in migration research: Explooring moorings a a schema.," Progress in Human Geography, vol. 19, no. 4, pp. 504 - 524, 1995.

[14] C. Hyeuk, "Consumer brand engagement by virtue of using Starbucks's branded mobile app based on grounded theory methodology," International Journal of Asia Digital Art \& Design, vol. 19, no. 4, pp. 91 97, 2016.
[15] M. Candi and R. Saemundsson, "Exploring the relationship between aesthetic design as an element of new service development and performance," The Journal of Product Innovation Management, vol. 28, no. 4, pp. 536-557, 2011.

[16] H. Xu, H. Teo, B. Tan and R. Agarwal, "The Role of Push-pull technology in privacy calculus: the case of location-based services," Journal of Management Information Systems, vol. 26, no. 3, pp. 135-174, 2009.

[17] Y. Chang and M. Polonsky, "The influence of multipel types of service convinience on behavioral intentions: The Mediating role of consumer satisfaction in a Taiwanese leisure setting," International Journal of Hospitality Management, vol. 31, no. 1, pp. 107-118, 2012.

[18] S. Hsu, J. Chang and C. Lee, "Designing Attractive gamification features for collaborative storytelling websites," Cyberpsychology, Behavior, and Social Networking, vol. 16, no. 6, pp. 426-435, 2013.

[19] M. Wang and X. Li, "Effect of the aesthetic design of icon on app download: evidence from an android market," Electronic Commerce Research, vol. 17, no. 1, pp. 82-102, 2017.

[20] C. Ye and R. Potter, "The Role of Habit in PostAdoption Switching of Personal Information Technologies: An Empirical Investigation," Communications of The Association for Information Systems, vol. 28, no. 1, pp. 585 - 610, 2011.

[21] I. Junglas and R. Watson, "Task-Technology fit for Mobile Locatable Information Systems," Decision Support Systems, vol. 45, no. 4, p. 104601057, 2008.

[22] C. Park and S. Ryoo, "An Empirical Investigation of End-Users switching toward Cloud Computing: A Two Factor Theory Perspective," Computers in Human Behavior, vol. 29, no. 1, pp. 160 - 170, 2013.

[23] A. Teo, G. Tan, K. Ooi, T. Hew and K. Yew, "The Effects of Conveninece ans Speed in Payment," Industrial Management and Data Systems, vol. 115, no. 2, pp. 311 - 333, 2015.

[24] V. Venkatesh, J. Thong and X. Xu, "Consumers Acceptance and Use Information Technology :

Extending The Unified Theory of Acceptance and Use of Technology," MIS Quarterly, vol. 36, no. 1, pp. 157 178, 2012.

[25] S. Hong and K. Tam, "Understanding the Adoption of Multipurpose Information Appliance: The Case of 
Mobile Data Services," Information Systems Research, vol. 17, no. 2, pp. 162 - 179, 2006.

[26] D. McFadden, "Economic Choices," American Econmic Review, vol. 91, no. 3, pp. 351 - 378, 2001.

[27] J. Bittner and J. Schipper, "Motivational Effects and Age Differences of Gamification in Product Advertising," The Journal of Consumer Marketing, vol. 31, no. 5, pp. 391 - 400, 2014.

[28] A. Darejeh and S. Salim, "Gamification Solutions to Enhance Software User Engagement: A Systematic Review," International Journal of Human - Computer Interaction, vol. 32, no. 8, p. 613, 2016.

[29] C. Hofacker, K. de Ruyter, N. Lurie, P. Manchanda and J. Donaldson, "Gamification and Mobile Marketing Effectiveness," Journal of Interactive Marketing, vol. 34, p. 25, 2016.

[30] L. Rodrigues, C. Costa and A. Oliveira, "Gamification: A Framework for Designing Software eBanking," Computer in Human Behavior, vol. 62, pp. $620-634,2016$

[31] R. Ganesh Pillai and V. Bindroo, "The Moderating Roles of Perceived Complementarity and Substitutability on the Perceived Manufacturing Diffculty-extention Attitude Relationship," Journal of Business Research, vol. 67, no. 7, pp. 1353 - 1359, 2014.

[32] J. Hagedoorn and N. Wang, "Is There Complementarity or Substitutability between Internal and External R\&D Strategies," Research Policy, vol. 41, no. 6, pp. 1072 - 1083, 2012.

[33] C. Dennis, C. Jayawardhena and E. Papamatthaiou, "Antecedents of Internet Shopping Intention and Moderating Effect of Substitutability," The International Review of Retail, Distribution, and Consumer Research, vol. 20, no. 4, pp. 411 - 430, 2010.

[34] L. White and V. Yanamandram, "Why the Customers Stay: Reason and Consequences of Inertia in Financial Services," Managing Service Quality, vol. 14, no. 2, pp. 183 - 194, 2004.

[35] Djaali, Psikologi Pendidikan, Jakarta: Sinar Garfika Offset, 2008.

[36] I. Ghozali, Structural Equation Modeling, Metode Alternatif dengan Partial Least Square (PLS), Semarang: Badan Penerbit Universitas Diponegoro, 2014.
[37] J. Hair, G. Hult, C. Ringle and M. Sarstedt, A primer on Partial Least Squares Structural Equation Modelling PLS-SEM, Thousand Oaks, CA : Sage, 2017.

[38] J. Hair, W. Black, B. Babin and R. Anderson, Multivariate Data Analysis, Essex: Pearson Education Limited., 2014.

[39] V. E. C. W. H. J. \&. W. H. Vinzi, Vinzi, V. E., Chin, W., HenseHandbook of Partial Least Squares: Concep, Methods, and Applications., Berlin Heidelberg: Springer-Verlag., 2010.

[40] N. Kock and P. Hadaya, "Minimum sample size estimation in PLS-SEM: The inverse square root and gamma-exponential methods," Information Systems Journal, vol. 28, no. 1, p. 227-261, 2018.

[41] J. Roldan and M. Sanchez-Franco, "Variancebased Structural Equation Modelling: Guideline for Using Partial Least Square in Information Systems Research," in Research Metodologies, Innovation and Philosophies in Software Systems Engineering and Information Systems, Hershey, PA, IGI Global, 2012, pp. 103-121.

[42] M. Sarstedt, J. Hair, C. Jun-Hwa, J.-M. Becker and C. M. Ringle, "How to Specify, Estimate, and Validate Highher Order Constructs in PLS-SEM," Australasian Marketing Journal, vol. 27, no. 3, pp. 197 - 211, 2019.

[43] J. E. Wieringa and P. C. Verhoef, "Understanding Customer Switching Behavior in a Liberalizing Service Market: An Exploratory Study," Journal of Service Research, vol. 10, no. 2, pp. 174 - 186, 2007.

[44] L. Wang, X. Y. Xin (Robert) Luo and Z. Qiao, "Easy come or easy go? Empirical evidence on switching behaviors in mobile payment applications," Information \& Management, vol. 56, 2019.

[45] Y. Jiang, L. Zhan and D. D. Rucker, "Power and Action Orientation: Power as a Catalyst for Consumer Switching Behavior," Journal of Consumer Research, vol. 41, pp. 183 - 196, 2014.

[46] E. E. Rigdon, "Rethinking Partial Least Square Path Modeling: In Praise of Simple Methods," Long Range Planning, vol. 45, no. 5 - 6, pp. 341 - 358, 2012. 